\title{
Projeto de turismo de base comunitária: comunidade tradicional do Bonete, Ilhabela (SP)
}

\author{
Community-Based Tourism Project: the traditional community of Bonete, \\ IIhabela (SP, Brazil)
}

\section{Mariane Carla Checon Salvador, Roberta Pedroso, Fátima Bezerra Bastos}

\begin{abstract}
RESUMO
A comunidade tradicional do Bonete, localiza-se no entorno do Parque Estadual da llhabela, no município de Ilhabela (SP). É formada por famílias caiçaras que mantém a tradição da pesca artesanal e atividades como o feitio de canoas, e o turismo, entre outras. Esta publicação visa trazer os resultados do projeto Turismo de Base Comunitária, organizado pelo Centro de Experimentação em Desenvolvimento Sustentável do Litoral Norte SP (CEDS/ LN), Convênio entre Unisantos, ONG's ambientalistas do ReaLNorte e Petrobrás com apoio do Instituto Costa Brasilis. Este projeto teve como objetivo desenvolver um modelo alternativo de desenvolvimento turístico no Litoral Norte, orientado pelos princípios da economia solidária, valorizando a cultura tradicional, fazendo do turismo de base comunitária uma estratégia de conservação ambiental, fortalecimento comunitário e fonte de renda. Através das Oficinas de Planejamento Participativo foram realizados o levantamento da oferta turística, a elaboração de um produto turístico de Base Comunitária, e a consolidação de um roteiro de visitação gerido pela comunidade.
\end{abstract}

PALAVRAS-CHAVE: Turismo de Base Comunitária; Comunidades Tradicionais; Geração de Renda; Conservação; Bonete.

\begin{abstract}
Bonete traditional community of is located in the surroundings of llhabela State Park, in Ilhabela, (SP, Brazil). It is formed by "caiçara" families (native inhabitants of the coast), who maintain traditional fishing practices and other activities such as canoe manufacturing, local commerce and tourism. This publication aims to bring the results of a Community Based Tourism project, organized by the Experimentation Center for Sustainable Development in the North Coast SP (CEDS/LN), in agreement with Unisantos, environmental NGOs and Real Norte Petrobras with support by Costa Brasilis Institute. This project aimed at developing an alternative model fortourism in the North Coast, by using the principles of social economy as guidelines, also by valuing traditional culture and using community-based tourism as a strategy for nature conservation, community empowerment and source of income. Participatory Planning Workshops were conducted to identify the tourist offer, develop a Community-Based Tourism product, and consolidate a cultural tour managed by the community.
\end{abstract}

KEYWORDS: Community-Based Tourism; Traditional Communities; Income Generation; Conservation; Bonete.

Página 1052 Revista Brasileira de Ecoturismo, São Paulo, v.6, n.5, nov 20I3-jan 20I4, pp.1052-I069.

Sociedade Brasileira de Ecoturismo. Rua Dona Ana, 138, Vila Mariana, São Paulo, SP - Brasil. E-mail: rbecotur@sbecotur.org.br; Tel. (55-II) 99196-7685 
Projeto de turismo de base comunitária: comunidade tradicional do Bonete, llhabela (SP)

\section{Introdução}

O Litoral Norte de São Paulo detém uma das maiores áreas contínuas de Mata Atlântica remanescente no Brasil, apresenta uma importante concentração de atrativos naturais e culturais e a presença de comunidades tradicionais, caiçaras, quilombolas e indígenas, aliados a um quadro de grandes desafios socioambientais (Figuras 1 e 2).

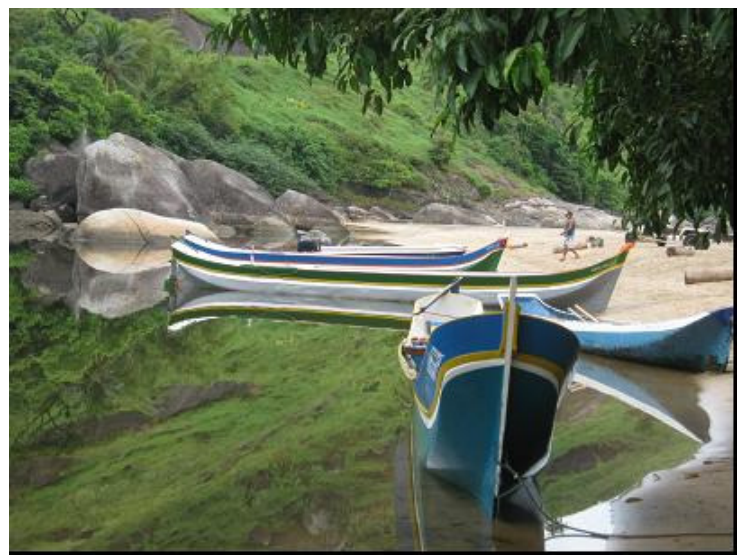

Figura 1: Canoas no Rio Nema. Figure 1: Canoas in the Nema River.
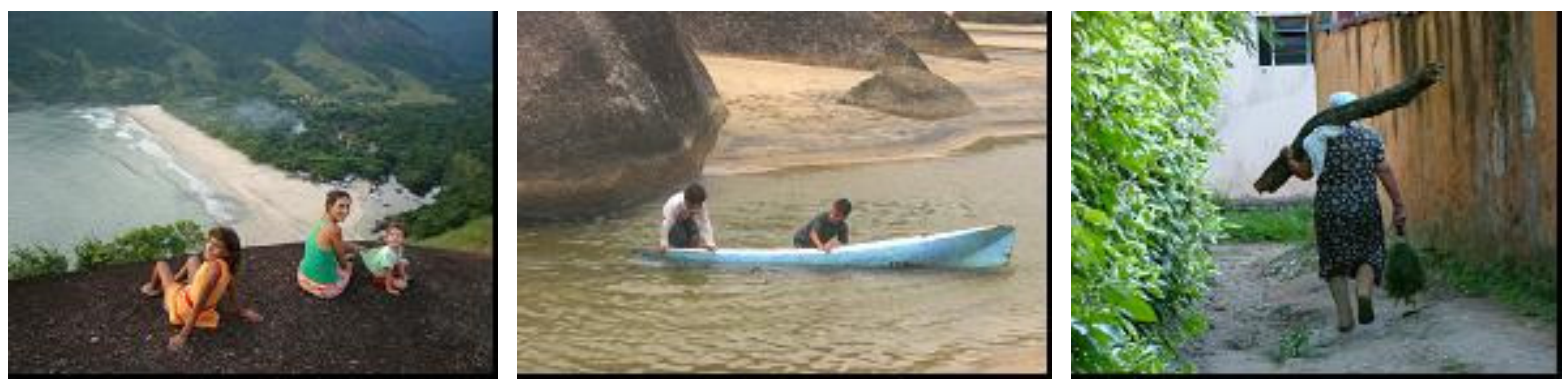

Figura 2: Moradores da comunidade do Bonete.

Figure 2: Bonete community residents.

Estes desafios levam a uma reflexão sobre o tipo de turismo desejável para a região. O desenvolvimento do Turismo de Base Comunitária (TBC) no Litoral Norte se mostra como alternativa aos projetos de turismo convencional e pode representar uma estratégia de conservação ambiental, fortalecimento comunitário e fonte de renda, na medida em que as comunidades são as principais protagonistas da atividade, participando do planejamento e da gestão do turismo. De acordo com alguns dos princípios do turismo responsável (SALVATI, 2003) o turismo deve ser parte de um desenvolvimento sustentável amplo e de suporte para a conservação e respeitar as culturas locais, promovendo benefícios e oportunidades para as comunidades locais.

Este artigo pretende disponibilizar informações sobre Turismo de Base Comunitária no Litoral Norte de São Paulo e trazer os resultados do projeto Turismo de Base Comunitária, organizado pelo Centro de Experimentação em Desenvolvimento Sustentável do Litoral Norte SP (CEDS/LN), Convênio entre Unisantos, ONG's ambientalistas do ReaLNorte e Petrobrás com apoio do Instituto Costa Brasilis.

O Projeto teve como objetivo desenvolver um modelo alternativo de turismo no

Página 1053 Revista Brasileira de Ecoturismo, São Paulo, v.6, n.5, nov 2013-jan 20I4, pp.1052-1069. 
Litoral Norte, orientado pelos princípios da economia solidária, valorizando a cultura tradicional, fazendo do turismo de base comunitária uma estratégia de conservação ambiental, fortalecimento comunitário e fonte de renda.

Ao final do Projeto esperou-se ter contribuído para consolidar o turismo de base comunitária numa área de influência do Parque Estadual de Ilhabela, introduzindo alternativas econômicas compatíveis com o desenvolvimento sustentável da região - com participação da população local - tendo como pano de fundo uma Unidade de Conservação da Mata Atlântica, servindo de modelo para outras áreas protegidas e seu entorno.

\section{Turismo de base comunitária}

Muitos conceitos estão relacionados com o turismo comunitário, dentre eles: turismo solidário, turismo responsável, sustentável, etc. Para fins deste projeto, foi adotado o seguinte conceito:

turismo realizado em áreas naturais, determinado e controlado pelas comunidades locais, que gera benefícios predominantemente para estas e para as áreas relevantes para a conservação da biodiversidade" (WWF, BRASIL, 2003, s/p).

A reflexão acerca desta temática envolve vários outros conceitos complexos e polêmicos, mas que não serão tratados em profundidade neste texto, porém, apenas para fundamentar esta análise, vale citar as considerações da OMT (Organização Mundial do Turismo) sobre o desenvolvimento do turismo sustentável.

A OMT (2003, p. 24), a partir da Agenda 21, cria a "Agenda 21 para Viagens e Turismo" e define que "o desenvolvimento do turismo sustentável atende as necessidades dos turistas de hoje e das regiões receptoras, ao mesmo tempo em que protege e amplia as oportunidades para o futuro. É visto como um condutor ao gerenciamento de todos os recursos, de tal forma, que as necessidades econômicas, sociais e estéticas possam ser satisfeitas sem desprezar a manutenção da integridade cultural, dos processos ecológicos essenciais, da diversidade biológica e dos sistemas que garantem a vida" (OMT, 2003, p.24 apud ORTIZ, 2005, p.128-129).

Quando se trata do desenvolvimento do turismo de base comunitária, a chance da sustentabilidade da atividade ser alcançada é maior que em outros modelos de desenvolvimento, já que este processo de desenvolvimento do TBC difere do que ocorre com a presença de grandes empreendedores, que exploram determinada localidade até o esgotamento de sua atratividade, fazendo com que o local atinja seu declínio e depois passam a explorar outro destino.

A comunidade não quer degradar o ambiente onde vive, local onde irá criar seus filhos. A sua relação de interdependência com os recursos é mais respeitosa que para o empresário que só visa lucros a curto prazo e normalmente não reside na destinação, deixando de divulgar o atrativo, quando este não lhe for mais lucrativo.

Página 1054 Revista Brasileira de Ecoturismo, São Paulo, v.6, n.5, nov 20I3-jan 20I4, pp.1052-I069. 
Palavras e expressões como participação, protagonismo social, empoderamento, afirmação cultural, benefícios diretos, ganham destaque nesse contexto e começam a se articular com o tema da conservação ambiental. É o que propõe Sansolo em sua análise sobre os paralelismos entre as políticas de proteção da natureza e de desenvolvimento turístico, principalmente no que diz respeito ao processo de descentralização e gestão compartilhada. A abertura para o turismo, que antes era vista como processo de aculturação, passa então a ser promovida como um veículo de reforço à etnicidade e revitalização cultural. [...] No Brasil há diferentes casos bem sucedidos de Turismo de Base Comunitária, em diferentes regiões e estados do Brasil (BARTHOLO; SANSOLO; BURSZTYN, 2009, p.17).

\section{Mapeamento das iniciativas de turismo de base comunitária no litoral norte de São Paulo}

Dentre os projetos envolvendo turismo de base comunitária em comunidades tradicionais identificados no Litoral Norte de São Paulo, havia: Projeto AICÁS Educação Ambiental na Praia da Almada (Ubatuba); Aoka - Operadora de Turismo Sustentável (Ubatuba); Roteiro Turístico do Mexilhão, na Praia da Cocanha (Caraguatatuba); Projeto Quilombo Fazenda Picinguaba, no Quilombo da Fazenda (Ubatuba); O Programa de Turismo Rural (SENAR - Serviço Nacional de Aprendizagem Rural), também no Quilombo da Fazenda (Ubatuba); e o Projeto Caiçaras, Indígenas e Quilombolas: construindo juntos o turismo cultural da Região da Costa Verde, realizado através do Fórum de Comunidades Tradicionais com recursos do Ministério de Turismo e implementado através da AMOC - Associação dos Moradores do Campinho, abrangendo comunidades tradicionais da Costa Verde (RJ) e do norte de Ubatuba, que fazem parte deste Fórum.

Atuando como grande catalisador das atividades de ecoturismo no Norte de Ubatuba (SP), destaca-se o Núcleo Picinguaba do Parque Estadual da Serra do Mar. O Núcleo é quem atualmente divulga e realiza o agendamento de trilhas no interior do Parque Estadual da Serra do Mar.

\section{Diagnóstico de turismo de base comunitária: litoral norte de São Paulo}

O projeto teve início em setembro de 2009. A princípio foram feitos os levantamentos de dados secundários e em seguida foram visitadas as comunidades identificadas até o mês de novembro para o levantamento dos dados primários.

Foram realizadas visitas em dez comunidades tradicionais do litoral norte paulista: comunidade caiçara da Barra Seca (Ubatuba); comunidade caiçara do Bonete (Ilhabela); comunidade quilombola da Praia da Caçandoca (Ubatuba); comunidade caiçara da Praia da Cocanha (Caraguatatuba); comunidade caiçara de Picinguaba (Ubatuba); comunidade caiçara do Porto Novo (Caraguatatuba); comunidade caiçara da Praia da Almada (Ubatuba); comunidade quilombola do Quilombo da Fazenda (Ubatuba); comunidade quilombola do Quilombo do Cambury (Ubatuba) e comunidade caiçara do Bairro São Francisco (São Sebastião). 
Salvador, M.C.C.; Pedroso, R.; Bastos, F.B.

Em campo foram observados os seguintes critérios: caracterização da comunidade; organização comunitária; centro comunitário; atividades desenvolvidas; projetos de turismo em andamento; apoio institucional; acesso; infraestrutura turística; infraestrutura básica e interesse no projeto.

O Quadro 1 apresentada a planilha com a pontuação de cada comunidade seguindo os critérios definidos neste ecoprojeto do CEDS/LN:

Quadro 1: Diagnóstico da oferta turística nas comunidades tradicionais do litoral norte de São Paulo.

Table 1: Tourist offer diagnosis in the communities in the north coast of São Paulo (Brazil).

\begin{tabular}{|c|c|c|c|c|c|c|c|c|c|c|c|c|c|}
\hline Comunidade & 용 & 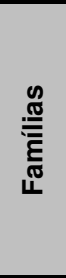 & 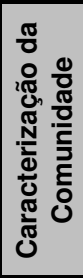 & 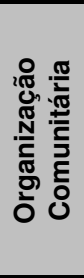 & 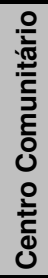 & 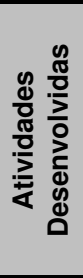 & 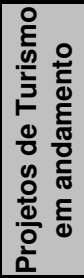 & 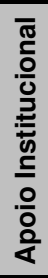 & $\begin{array}{l}\text { O } \\
\text { \& } \\
\text { ¿ }\end{array}$ & 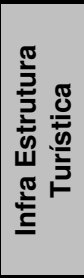 & 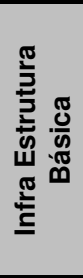 & 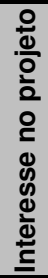 & $\begin{array}{l}\frac{\pi}{7} \\
\text { है }\end{array}$ \\
\hline Barra Seca & Caiçara & 150 & 2 & 1 & 1 & 2 & 1 & 3 & 3 & 1 & 2 & 2 & 1,8 \\
\hline Bonete & Caiçara & 76 & 3 & 2 & 3 & 3 & 3 & 2 & 1 & 2 & 3 & 3 & 2,5 \\
\hline Caçandoca & Quilombola & 53 & 2 & 3 & 2 & 2 & 3 & 1 & 1 & 1 & 2 & 1 & 1,8 \\
\hline Cocanha & Caiçara & 14 & 2 & 2 & 2 & 2 & 3 & 3 & 3 & 2 & 2 & 1 & 2,2 \\
\hline Picinguaba & Caiçara & 75 & 2 & 3 & 1 & 2 & 1 & 2 & 2 & 2 & 2 & 1 & 1,8 \\
\hline Porto Novo & Caiçara & 34 & 1 & 3 & 1 & 2 & 3 & 3 & 3 & 2 & 2 & 2 & 2,2 \\
\hline Praia da Almada & Caiçara & 45 & 2 & 2 & 3 & 2 & 1 & 3 & 2 & 2 & 2 & 1 & 2 \\
\hline Quilombo da Fazenda & Quilombola & 49 & 3 & 2 & 1 & 3 & 2 & 3 & 2 & 1 & 2 & 3 & 2,2 \\
\hline Quilombo do Camburi & Quilombola & 60 & 3 & 2 & 3 & 3 & 2 & 3 & 1 & 1 & 2 & 2 & 2,2 \\
\hline São Francisco & Caiçara & 135 & 1 & 3 & 1 & 2 & 1 & 3 & 3 & 2 & 3 & 2 & 2,1 \\
\hline
\end{tabular}

Conforme se pode observar, a comunidade do Bonete obteve maior pontuação, sendo, portanto a comunidade selecionada para o desenvolvimento das oficinas de planejamento participativo.

\section{Oficinas de planejamento participativo}

Os objetivos do primeiro módulo (conceitos e levantamento da oferta turística) foram: 1) construir conceitos relevantes ao planejamento participativo de turismo de base comunitária; 2) discutir os princípios de turismo de base comunitária no Bonete conforme outras organizações (TURISOL); 3) levantar a oferta turística no Bonete; e 4) identificar necessidades para tornar recursos em atrativos.

Foi importante fazer uma apresentação do projeto questionando a finalidade do planejamento e a diferença entre turismo com e sem planejamento. Neste momento foi reconhecido o papel fundamental da comunidade do Bonete durante o processo de planejamento para o desenvolvimento da atividade turística, pois são eles os maiores conhecedores dos atrativos que podem ser oferecidos e também aqueles que podem ser impactados negativa ou positivamente pela atividade turística, daí a necessidade de um planejamento participativo, união e organização. Logo no início também foram levantadas as expectativas e dado um retorno sobre o que o projeto abordaria ou não. 
Projeto de turismo de base comunitária: comunidade tradicional do Bonete, llhabela (SP)

\section{Oficina "construção de conceitos"}

Para se estabelecer uma linguagem turística comum e também a fim de homogeneizar os conhecimentos dos participantes, a primeira oficina realizada foi a de "Construção de Conceitos", na qual foram construídos coletivamente os conceitos para as palavras: "comunidade", "tradição", "turismo", e "turismo de base comunitária" Figura 3). Os resultados foram os seguintes conceitos:

- Comunidade: "Um grupo de pessoas que vive em um mesmo local (bairro)"; "É sempre viver em grupo, um grupo comum" ;"Onde todos se conhecem"; "Pessoas que se identificam"; "Solidariedade". "Participação"; "Responsabilidade coletiva para tornar a vida melhor";

- Tradição: "O que é passado de geração para geração"; "Manter coisas antigas"; "Forma de manter sua cultura". Exemplos de tradição: "fazer canoa, remo, farinha de mandioca, rede, pescaria, comida caiçara, buscar lenha";

- Turismo, na visão do turista e da comunidade. Para o turista: "Preservar a natureza"; "Conhecer lugar diferente"; "Chegar em um lugar e ser bem atendido"; "Conservar o local"; "Opções de esporte e lazer, segurança, opções de alimentação e estadia, pontos turísticos"; Para a comunidade: "Meio que gera trabalho, viagem, pesca, etc...Para quem tem camping gera dinheiro de acampamento, comida, convive melhor com as pessoas, amizade, aluguel de casa, quartos, pousada, melhor qualidade de vida, quer ser respeitada";

- Turismo de Base Comunitária: "Traz benefícios para a comunidade"; "União / oportunidade para todos"; "Gera emprego para a comunidade"; "O turista vem visitar a comunidade para ver o seu modo de vida"; "É o turismo voltado para as tradições da comunidade"; "Interação dos turistas com a comunidade"; "O turista comunitário é o que se inteira com a comunidade e suas belezas naturais"; "Há distribuição de renda".
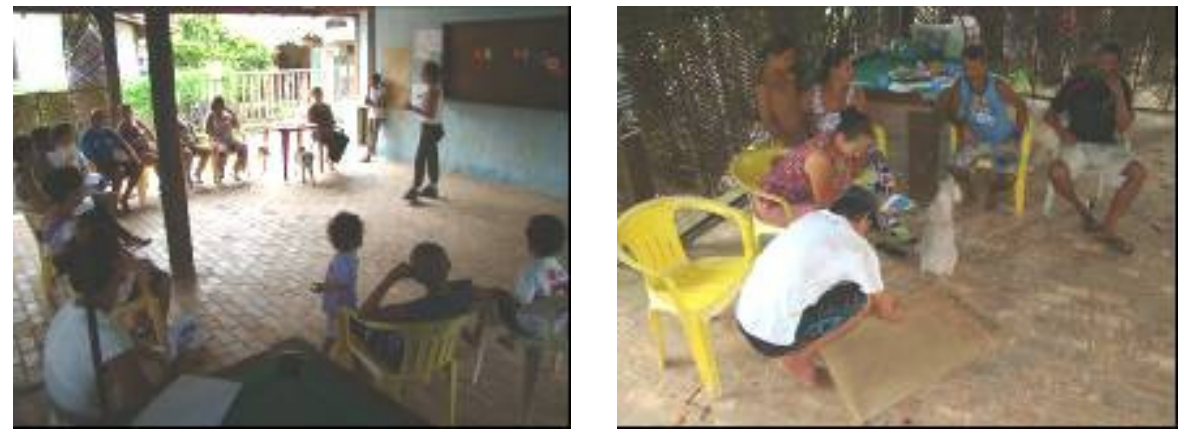

Figura 3: Oficina "construção de conceitos".

Figure 3: Workshop "building concepts."

Para concluir esta etapa e dar um retorno sobre o conceito construído do termo "Turismo de Base Comunitária", os resultados foram comparados com os princípios do Turismo Responsável proposto pelo Manual de Ecoturismo de Base Comunitária (WWF - 2003 p.24-25):

- O turismo deve ser parte de um desenvolvimento sustentável amplo e de suporte para a conservação;

Página 1057 Revista Brasileira de Ecoturismo, São Paulo, v.6, n.5, nov 2013-jan 20I4, pp.1052-1069. 
- O turismo deve usar os recursos naturais de modo sustentável;

- O turismo deve eliminar o consumo insustentável e minimizar a poluição e o desperdício;

- O turismo deve respeitar as culturas locais e prover benefícios e oportunidades para as comunidades locais.

Ao longo dos módulos foram realizados jogos para sensibilizar quanto a determinados conceitos relacionados ao turismo de base comunitária. Para desenvolver esses conceitos, foi utilizada como ferramenta a dinâmica da "teia da vida" ou "teia alimentar" adaptada de metodologias utilizadas em atividades de educação ambiental, também foi inserida a atividade de "jogos de papéis", cada participante representou um ator importante no contexto do Turismo de base comunitária. O objetivo era sensibilizar a comunidade quanto a importância de cada ator social, estabelecendo relações de interdepêndencia no âmbito do conceito de turismo de base comunitária. Para tanto, os participantes foram dispostos em círculo, cada um assumiu o papel de um ator comunitário ( Canoeiro; Turista; Professora; Dono de Restaurante; Dono do Quiosque, Parque Estadual; Artesão e Dono de Pousada). Com um novelo de lã partindo de um dos atores, cada um foi segurando uma ponta da lâ e jogando para o próximo ator, formando assim uma teia. Para finalizar os mediadores proporam uma reflexão sobre essa dinâmica, trabalhando alguns conceitos como: Interdepêndencia; conexão; coletividade

Como resultados, após breve reflexão, os participantes relataram sua percepção de oportunidades; da importância da união onde se sentem interligados e em grupo conseguem se fortalecer como uma rede, na função de pegar peixe ou cercar uma horta; que formam uma cadeia; também a ideia de que se atraem pelos objetivos; também visualizaram a ideia de um labirinto, que é preciso achar uma saída juntos.

\section{Oficina "levantamento da oferta turística"}

Somente após o conhecimento do potencial atrativo, das lacunas e dificuldades para implementação e da visão e expectativas da comunidade é que um programa ou projeto de ecoturismo deve ser implantado (BORGES, 2003, p.90).

Borges (2003, p.89) considera a realização do inventário da oferta turística como um dos fatores determinantes para o sucesso do planejamento; representa a primeira etapa deste processo. O mesmo autor lembra que "inventariar é pesquisar e relacionar, de modo quantitativo e qualitativo os bens ( $p$. ex. atrativos naturais ou culturais, acessos) e serviços ( $p$. ex. meios de hospedagem e guias) de uma determinada região".

Oferta turística pode ser entendida como bens e serviços oriundos da estrutura de atrativos, utilidade pública, geral e turística de uma localidade que, combinados de diferentes maneiras, permitem conformar produtos turísticos (BALANZÁ; NADAL, 2003).

Página 1058 Revista Brasileira de Ecoturismo, São Paulo, v.6, n.5, nov 20I3-jan 20I4, Pp.1052-I069. 
Para a oficina de levantamento de oferta turística do Bonete, primeiramente foram discriminados os componentes da oferta turística (recurso turístico, atrativo turístico, equipamento turístico, equipamento de apoio, serviço turístico e serviço de apoio), de maneira que estas informações contribuíssem para a análise do turismo e também para uma que a comunidade tivesse acesso à linguagem de profissionais da área e facilitar o planejamento. Usou-se uma linguagem simples, seguindo orientações do Manual Indígena de Ecoturismo (MMA, 1997) sobre levantamento da oferta turística. do Bonete.

Abaixo são apresentados os recursos turísticos levantados junto à comunidade

- Culturais: casa da farinha / produção de farinha de mandioca; peixe seco cultivo de alimentos; artesanato; pescarias; confecção de canoas; confecção de rede de pesca; confecção de peneira, tipiti, chapéu, balaio; fabricação de remos; caminho do Estevão;

- Naturais: Toca do Nego e Cachoeira do Saquinho.

Abaixo temos os atrativos turísticos levantados junto à comunidade do Bonete.

- Culturais: Festa de Santa Verônica; praça da conversa mole e roda de conversa (Seu Jessy);

- Naturais: Praia boa para surfe; mar bom para mergulho; trilhas (fauna e flora) e cachoeiras.

Quando o turista está viajando ele também precisa de serviços turísticos, que são atividades desenvolvidas para eles por pessoas da comunidade, e também serviços de apoio, aqueles que servem a toda a comunidade, mas que também são importantes para o turista, como a limpeza das ruas. Exemplos de serviços turísticos: passeio de lancha; monitor ambiental e passeio de canoa. Foram identificados também os equipamentos turísticos e os equipamentos de apoio do Bonete:

- Equipamentos turísticos: Pousada Canto Bravo; Pousada Porto Bonete; Pousada Margarida; Pousada da Rosa; Camping Guapuruvu; Camping da Vargem - Eugênio; Restaurante e Camping da Roseli Restaurante do Martin; Restaurante Mac Bonet's; Quiosque do Totó; Quiosque do Beto Cação; Quiosque Swell (na praia); Petiscaria Nema; Bambus Bar.

- Equipamentos de apoio: Bar do Sílvio; Mc Bone's; Posto de saúde; Telefone público e Internet.

É muito importante para o turista saber se encontrará, no local aonde ele vai: infraestrutura básica - construções e serviços públicos para atender as necessidades básicas dos moradores e também dos visitantes; e infraestrutura de acesso, para chegar e voltar em segurança. O Bonete possui:

- Infraestrutura básica: telefone público, coleta de lixo etc.

- Infraestrutura de acesso: Estrada do Bonete - SP 131, que é na verdade uma trilha de 20.000 metros (único acesso por terra e que não circula veículos); transporte em lancha e canoa de particulares. Esta dificuldade de acesso é inclusive o que manteve a cultura tradicional desta comunidade. 
Depois de levantada a oferta turística da comunidade foi elaborado com os participantes da oficina o Quadro 2, identificando o que falta para transformar os recursos turísticos em atrativos, bem como responsáveis e potenciais parceiros para tal.

Quadro 2: Levantamento da oferta turística.

Table 2: Inventory of Tourist Attraction.

\begin{tabular}{|c|c|c|c|}
\hline \multicolumn{2}{|c|}{$\begin{array}{c}\text { COMPONENTES DA OFERTA } \\
\text { TURÍSTICA } \\
\end{array}$} & O QUE FALTA? & $\begin{array}{l}\text { RESPONSÁVEL / } \\
\text { PARCEIROS }\end{array}$ \\
\hline \multirow{3}{*}{$\begin{array}{l}\text { RECUR } \\
\text { SO } \\
\text { NATUR } \\
\text { AL }\end{array}$} & $\begin{array}{l}\text { Produção da farinha } \\
\text { de mandioca } \\
\text { Casa da farinha }\end{array}$ & $\begin{array}{l}\text { Pessoas qualificadas para a produção } \\
\text { da farinha de mandioca } \\
\text { Motivação dos jovens }\end{array}$ & $\begin{array}{l}\text { ASSOBI / moradores } \\
\text { mais antigos / } \\
\text { FUNDACI }\end{array}$ \\
\hline & Artesanato & $\begin{array}{l}\text { Qualificação: pintura, bordado, } \\
\text { produção de tipiti, balaio, peneira, } \\
\text { gamela, canoinha (souvenir), cuia, remo } \\
\text { para decoração, pilão, rede. }\end{array}$ & $\begin{array}{l}\text { Alexandre Xavier } \\
\text { (artesão) / ASSOBI / } \\
\text { SEBRAE / Sérgio } \\
\text { (produção de rede) } \\
\end{array}$ \\
\hline & Produção de canoas & $\begin{array}{l}\text { Espaço físico } \\
\text { Licença para extração da tora e/ou } \\
\text { doações }\end{array}$ & $\begin{array}{l}\text { ASSOBI / Parque / } \\
\text { Secretaria do M.A. / } \\
\text { FUNDACI / moradores } \\
\text { que produzem canoas }\end{array}$ \\
\hline \multirow{4}{*}{$\begin{array}{l}\text { RECUR } \\
\text { SO } \\
\text { CULTU } \\
\text { RAL }\end{array}$} & Caminho do Estevão & $\begin{array}{l}\text { Articulação entre ASSOBI e o Parque } \\
\text { Reabrir a trilha com infra-estrutura }\end{array}$ & $\begin{array}{l}\text { Parque (responsável) } \\
\text { ASSOBI (parceira) }\end{array}$ \\
\hline & $\begin{array}{l}\text { Trilha Bonete - } \\
\text { Castelhos (direto) }\end{array}$ & $\begin{array}{l}\text { Reabrir a trilha com infra-estrutura } \\
\text { (ponte, sinalização, etc.) }\end{array}$ & PARQUE / ASSOBI \\
\hline & $\begin{array}{l}\text { Toca do Nego } \\
\text { (recurso natural / } \\
\text { cultural) }\end{array}$ & Reabrir o acesso para o salão principal & FUNDACI / ASSOBI \\
\hline & $\begin{array}{l}\text { Cachoeira do } \\
\text { Saquinho }\end{array}$ & $\begin{array}{l}\text { Trazer consultoria de especialista em } \\
\text { turismo de aventura em parceria com o } \\
\text { parque e prefeitura }\end{array}$ & $\begin{array}{l}\text { Parque / Prefeitura / } \\
\text { ASSOBI }\end{array}$ \\
\hline \multirow[b]{2}{*}{$\begin{array}{l}\text { EQUIPA } \\
\text { MENTO } \\
\text { DE } \\
\text { APOIO }\end{array}$} & Posto policial & $\begin{array}{l}\text { Espaço físico } \\
\text { Pessoal deslocado pra cá }\end{array}$ & $\begin{array}{l}\text { Prefeitura / Governo do } \\
\text { Estado }\end{array}$ \\
\hline & Posto de saúde & $\begin{array}{l}\text { Soro antiofídico; preservativos; } \\
\text { remédios; equipamentos; profissionais } \\
\text { qualificados para revezamento e } \\
\text { abertura do posto nos finais de semana } \\
\text { e feriados }\end{array}$ & Prefeitura \\
\hline $\begin{array}{l}\text { INFRA- } \\
\text { ESTR. } \\
\text { DE } \\
\text { ACESS } \\
\text { O }\end{array}$ & $\begin{array}{l}\text { Trilha do Bonete } \\
\text { (SP 131) }\end{array}$ & $\begin{array}{l}\text { Melhoria / implantação de infra-estrutura } \\
\text { para passagem de pedestres e carros } \\
\text { oficiais autorizados }\end{array}$ & $\begin{array}{l}\text { Parque / Prefeitura / } \\
\text { Governo do Estado / } \\
\text { ASSOBI / Câmara } \\
\text { Técnica de } \\
\text { Comunidades } \\
\text { Tradicionais }\end{array}$ \\
\hline $\begin{array}{l}\text { INFRA- } \\
\text { EST. } \\
\text { BÁSICA }\end{array}$ & Energia elétrica & $\begin{array}{l}\text { Articulação com os órgãos responsáveis } \\
\text { Consenso na comunidade }\end{array}$ & $\begin{array}{l}\text { ASSOBI / Câmara } \\
\text { Técnica de } \\
\text { Comunidades } \\
\text { Tradicionais / Governo } \\
\text { Federal }\end{array}$ \\
\hline
\end{tabular}

Página 1060 Revista Brasileira de Ecoturismo, São Paulo, v.6, n.5, nov 20I3-jan 20I4, Pp.I052-I069. 
Antes do exercício de levantamento da oferta do Bonete cada participante da oficina desenhou sua mão, escreveu e falou primeiramente algo que já fez pelo Bonete com suas mãos e em seguida, repetiu a atividade para responder à questão do que pode fazer pelo turismo comunitário no Bonete. Os resultados foram os seguintes:

- "Esta mão já ajudou algumas pessoas a conseguirem o seu diploma de ensino médio. Ajudou a comunidade a ter internet. Ajudou e ainda ajuda a organizar algumas coisas no bairro, pois ela ainda participa da associação" (Participante A);

- "Ser receptivo com as pessoas, receber bem as pessoas, dar informações, ajudar a preservar, não jogar lixo no chão para que o lugar continue sempre bonito" (Participante B);

- "Esta mão cumprimenta pessoas muito importantes e queridas pra mim e ensina os locais que os turistas procuram" (Participante C);

- "Esta mão vende produtos alimentícios, cumprimenta os turistas na praça da conversa mole" (Participante D)

O segundo módulo (identificação de valores da comunidade e elaboração de produto de Turismo de Base Comunitária e roteiros) teve como objetivos: 1) identificar os valores imprescindíveis da comunidade do Bonete e promover discussão acerca da maneira que estes valores podem ser incorporados e respeitados no desenvolvimento do turismo na comunidade; 2) exercitar a elaboração de roteiros na comunidade.

\section{Oficina "identificação de nossos valores"}

Às comunidades locais recomenda-se fortalecer, estimular e encorajar a habilidade da comunidade em manter e utilizar conhecimentos tradicionais que sejam relevantes para a atividade do ecoturismo, como o artesanato, a agricultura, o folclore, a culinária e demais atividades que utilizam os recursos locais de forma sustentável (DECLARAÇÃO DE ECOTURISMO DE QUEBEC - 2002 apud WWF, 2003).

Uma parte muito importante, que antecede o planejamento em si, é uma reflexão sobre os valores da comunidade e discussão acerca da maneira como estes valores podem ser respeitados, incorporados e até mesmo fortalecidos com o desenvolvimento do turismo.

Com o objetivo de levantar os valores da comunidade, os participantes da oficina deveriam refletir e com os olhos fechados visualizar algo especial, de grande valor na comunidade, que deveria ser conservado para as futuras gerações. Simbolicamente foi utilizado um baú, dentro do qual foram depositadas fichas de papel com os tais valores nelas escritos. Os resultados foram os seguintes: "a própria natureza preservada - o Rio Nema, a praia (limpa e linda), o Canto Bravo (formação rochosa), as ondas, a mata, a piscina natural, o mirante, entre outros; também alguns 
costumes - como a pesca artesanal, a fabricação de farinha de mandioca, a luz elétrica gerada através da pequena represa e gerador; família; união; cooperação; lendas e histórias"

Para ilustrar a possibilidade de transportar os valores da comunidade para o desenvolvimento de um turismo foi utilizada a figura de uma canoa, assim, ao serem revelados os valores eles eram colocados dentro de uma canoa (feita de papel).

Com o objetivo de discutir a parte de cada um dos participantes da oficina para contribuir para o fortalecimento desses valores ao incorporá-los no turismo foi utilizado o símbolo de um remo - que representou o esforço de cada um. As respostas foram variadas. Os adultos disseram que "poderiam manter costumes como a fabricação de farinha de mandioca, confecção de tipitis, canoas, remos e redes; conservar a natureza ao trabalhar com educação ambiental, passar conhecimento para os filhos, conhecer histórias e lendas, cuidar do lixo e esgoto; também poderiam realizar passeios de canoa e até surgiu a ideia de montar um centro cultural para expor a cultura (em parceria com a prefeitura)." As crianças, que participaram ativamente da oficina, disseram que eles "poderiam contribuir para fortalecer os valores ao: preservar a natureza - mata, rio, mar e animais, destinando o lixo corretamente e pedindo aos turistas para serem responsáveis pelo lixo que geram; pescar, surfar, ajudar turistas, cuidar do telefone, pedir aos pais para que contem histórias, continuar com as tradições - farinha, artesanato, canoa etc.; e não permitir que turistas consumam drogas no Bonete."

Chegou-se à conclusão que cada um pode fazer muita coisa, mas também perceberam que há necessidade de qualificação e parcerias, o que foi discutido, desta vez com o auxílio da figura do mar, para simbolizar os caminhos e desafios que a comunidade poderá encontrar no desenvolvimento do turismo de base comunitária. Sobre a necessidade de qualificação foram sugeridos: "cursos para montagem de site/blog, educação ambiental, idiomas, monitor ambiental, cálculo de preço, gestão de turismo de base comunitária, artesanato, primeiros socorros, organização comunitária, atendimento e culinária. Também sentem a necessidade da criação de um site ou blog. Acham que parcerias com SEBRAE, Sr. Carlos, prefeitura, parque e ONG's também podem contribuir.

Enfim, notou-se que os valores do Bonete, identificados pelos participantes da oficina, são os mesmos que o turista que procura por turismo de base comunitária busca e gosta de vivenciar, logo, para o desenvolvimento de um turismo responsável no qual o público alvo pode contribuir para o fortalecimento dos valores da comunidade é imprescindível a manutenção desses mesmos valores. Também percebeu-se que cada um da comunidade pode contribuir muito neste rumo do turismo de base comunitária ao fazer coisas que gostam e que é bom não só para o turista, mas principalmente para a própria comunidade. Concluiu-se ainda que mais qualificação e parcerias são muito importantes para o desenvolvimento de um turismo melhor para todos.

\section{Oficina elaboração de produto de Turismo de Base Comunitária}

Utilizando como referência Janer e Mourão (2003), nesta oficina destacamos os passos básicos para a elaboração de produtos de turismo de base comunitária, aplicando conceitos universais de marketing. Esta Oficina foi a que teve maior número de pessoas e a participação de todos foi muito apreciada.

Página 1062 Revista Brasileira de Ecoturismo, São Paulo, v.6, n.5, nov 20I3-jan 20I4, Pp.1052-1069. 
Foram abordados os seguintes conceitos:

- Marketing (mkt) - é uma atividade humana que tem como objetivo satisfazer necessidades e desejos por meio de processos de intercâmbio;

- 4 P's de marketing: produto, preço, praça e promoção.

Usando o conceito dos P's, foi feita uma análise coletiva sobre se o produto será desenhado para um grupo de terceira idade ou um grupo escolar? Preço - o preço será popular ou exclusivo? Praça ou distribuição - a estratégia de distribuição será de vender direto ao turista ou via intermediários (agências; operadoras de viagem)?Promoção - será feita por meio de folders, anúncios, divulgação?

Para a elaboração do produto foram abordados nove passos principais para facilitar a logística de como se faz um produto turístico, considerando: acesso, transporte, alimentação, hospedagem, condutores, seguro-viagem, informações, equipamentos necessários, além de Ficha de Saúde, Termo de Responsabilidade, etc.

\section{Oficina "elaboração de roteiro"}

Munidos de prancheta, caneta e câmera fotográfica o grupo saiu em busca de potenciais atrativos para a elaboração de um roteiro.No Quadro 3 (página seguinte), seguem as fotos e comentários sobre algumas das atividades turísticas que se pode fazer no Bonete.

Após a atividade de levantamento e registro dos atrativos do Bonete, foram redigidos dois roteiros durante o exercício para sua elaboração: Bonete Tradição Caiçara e Descobrindo as riquezas do Bonete.

O último módulo do Curso (bom atendimento no turismo; dicas para um bom condutor de turismo e consolidação de um roteiro para o Bonete) foi composto por 3 oficina (Figura 4): 1) "Bom atendimento no turismo": primeiramente foi mostrado um episódio do vídeo "Meu negócio é turismo" da Fundação Roberto Marinho e Ministério do Trabalho e Emprego, que mostrou exemplos de bom atendimento no turismo, além de revisar alguns conceitos trabalhados em oficinas anteriores. Em seguida, juntos discutimos: o porquê de uma boa prestação de serviços, quem são os turistas e o que eles esperam encontrar, princípios de uma boa comunicação com o turista, o que se espera de um atendimento com qualidade, sete erros que caracterizam um atendimento sem qualidade e qualidades de um bom prestador de serviços; 2) "Consolidação de um roteiro": considerou-se muito importante consolidar algum roteiro no Bonete para deixá-lo pronto para a comercialização. O resultado desta oficina foi a formatação de um roteiro cultural e opções de atividades de ecoturismo; e 3) "Condutor de visitantes": utilizando o Manual de guia de Turismo EMBRATUR, foram usadas fichas que ajudaram a destacar que dentre os deveres e responsabilidades do Condutor, está a de usar sua própria iniciativa e bom senso, a fim de desenvolver suas habilidades pessoais na função que ocupa, e que, portanto, algumas características são essenciais. 
Salvador, M.C.C.; Pedroso, R.; Bastos, F.B.

Quadro 3: Levantamento dos atrativos da comunidade.

Table 3: Inventory of Tourist Attractions in the community.

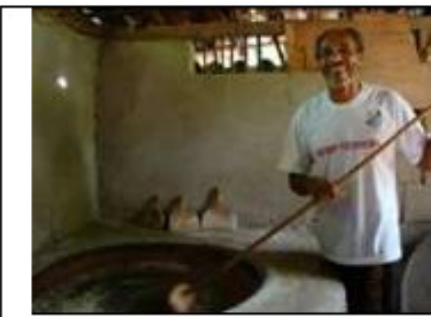

Forno na casa de farinha do Seu Américo

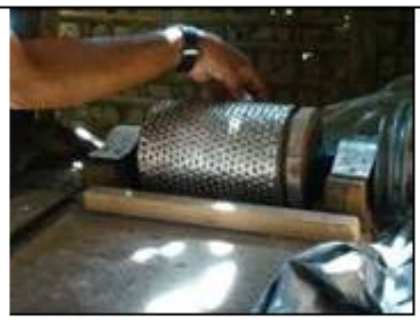

Ralador com motor (a pessoa que rala é chamada "cebadeira")

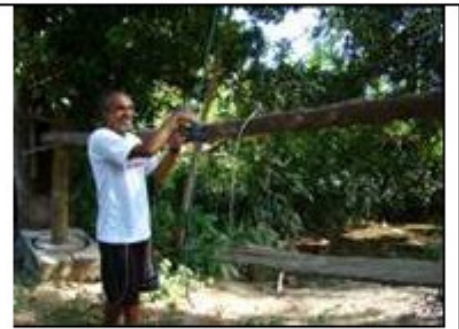

Prensa. A duração do processo de fazer farinha é de um dia: primeiro rala a mandioca, depois coloca a massa no tipiti, prensa, e após secar vai ao coxo e depois para o forno. A água da farinha (mandiquera) é utilizada para fazer tapioca.

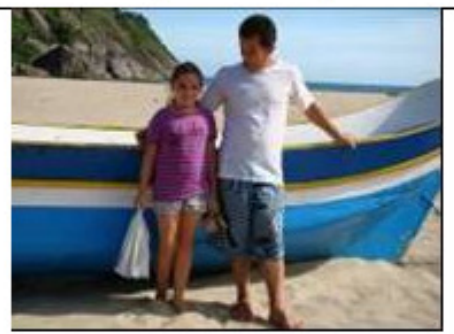

Canoeiro Moisés que faz canoas e ensinou seu filho a fazer também. Ele já foi para a França ensinar a fazer canoa.

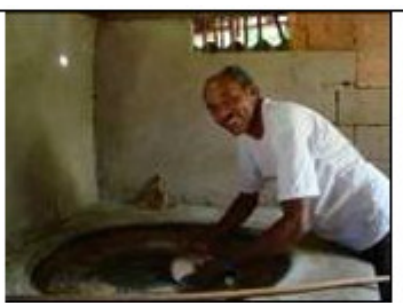

Pás para misturar a farinha

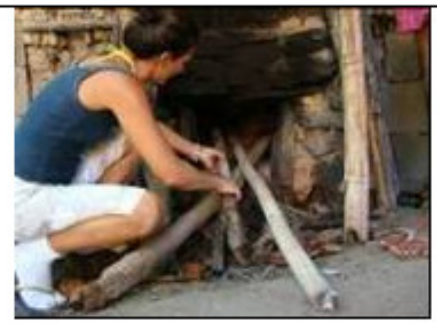

Forno visto pelo lado de fora

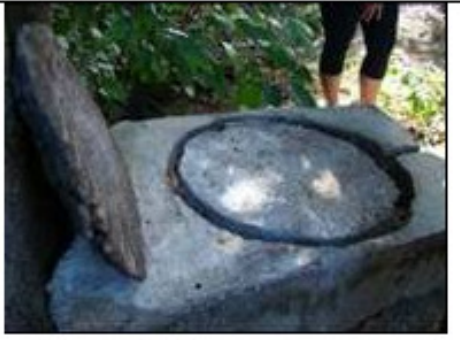

"queijo" de madeira para ser colocado em cima do tipiti. Outros rolos de madeira são colocados em cima que serão o apoio para um tronco maior que fará o peso para prensar.

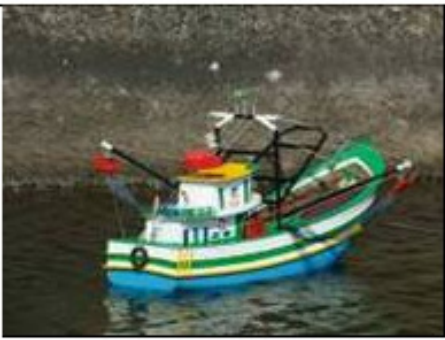

O barco miniatura fabricado por Seu Osmar.

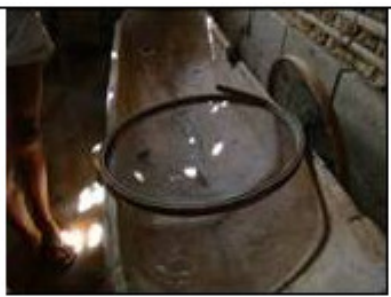

Coxo para colocar a farinha ralada

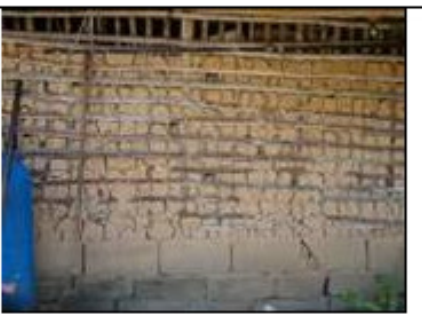

Parede de pau a pique da casa da farinha

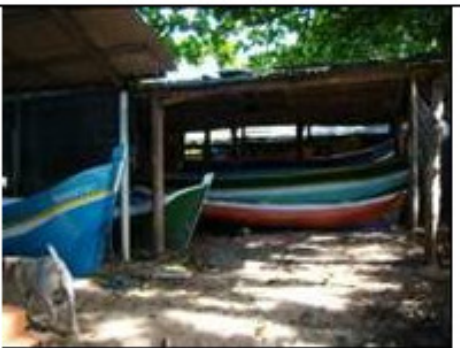

Canoas: a maioria das canoas possui nomes femininos, geralmente das esposas ou filhas.

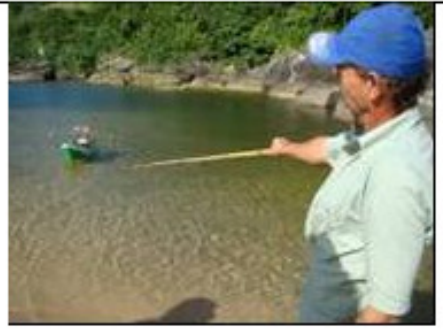

Seu Osmar e seu barco miniatura. Ele faz artesanato: remo caiçara, barco de arraste, canoinha. 
Projeto de turismo de base comunitária: comunidade tradicional do Bonete, llhabela (SP)

...continuação.

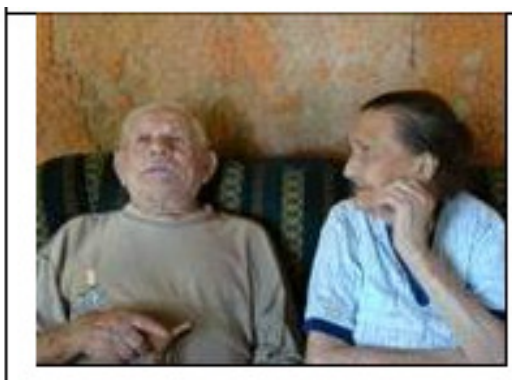

Sr. Jessy e sua esposa D. Jovita. O morador mais antigo do Bonete. Contador de histórias: de sua repreensão quando se gabava de suas caças mentirosas a um agente florestal, a origem do nome Bonete, a Toca do Nego, os naufrágios.

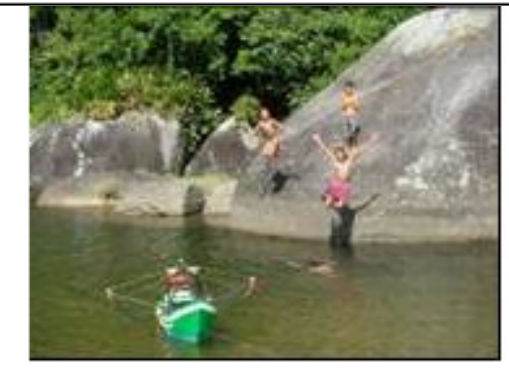

Rocha de onde as crianças pulam no Rio Nema.

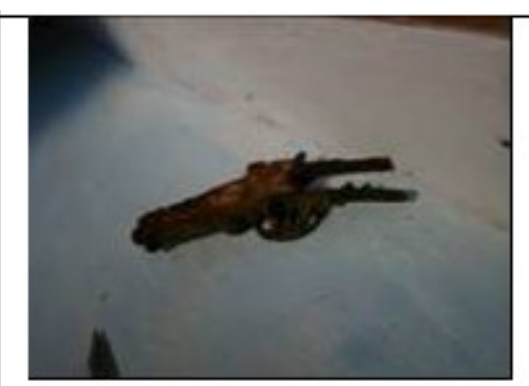

Arma antiga oxidada, provavelmente pertenceu a piratas

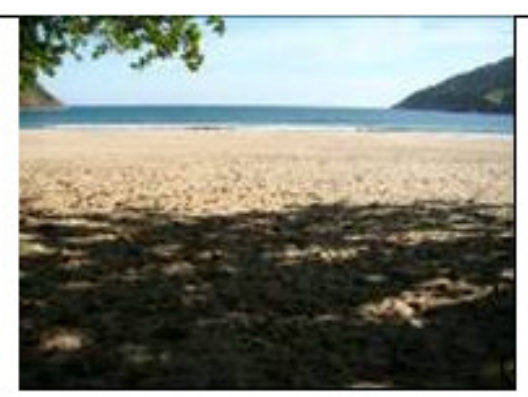

Praia

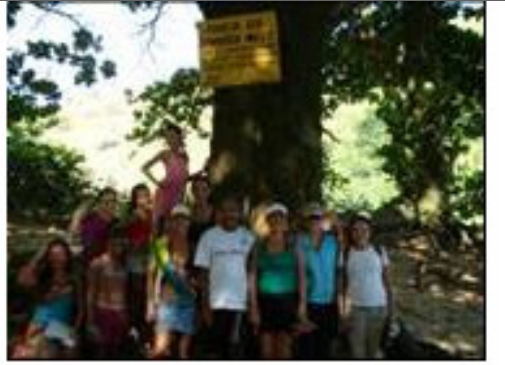

Praça da conversa mole

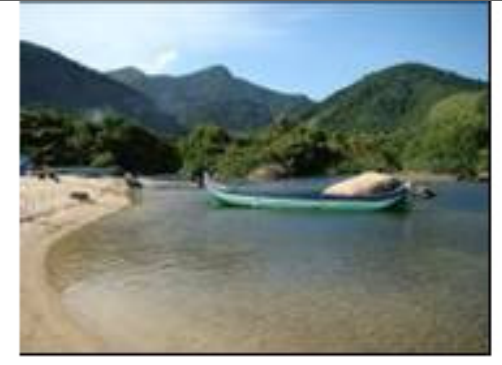

Rio Nema

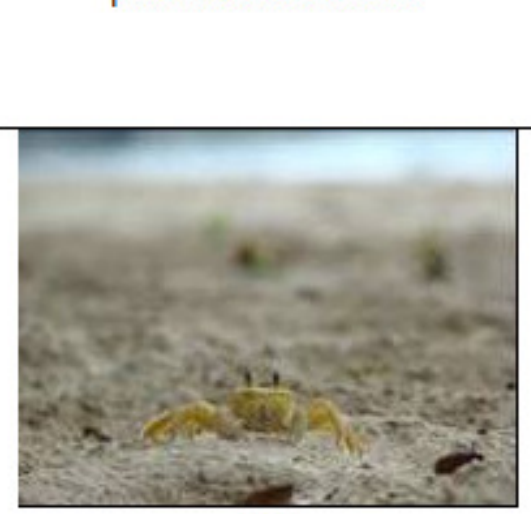

Siri

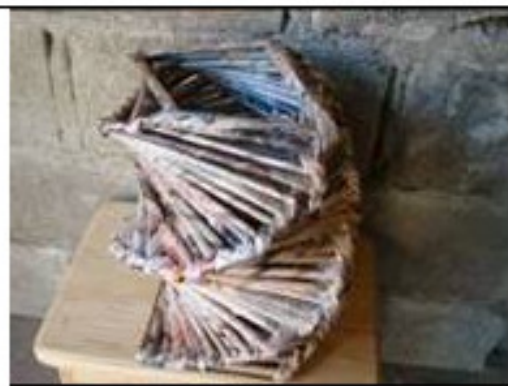

Artesanato de jornal feito por Allan

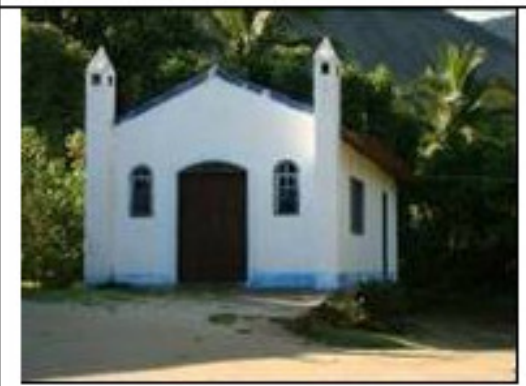

Igreja de Santa Verônica, aprox. 100 anos. Festa em homenagem à Santa em 08 de julho: há tocadores, forró, comidas, levantamento de mastro - duração 2 dias.

Continua... 
Salvador, M.C.C.; Pedroso, R.; Bastos, F.B.

...continuação.

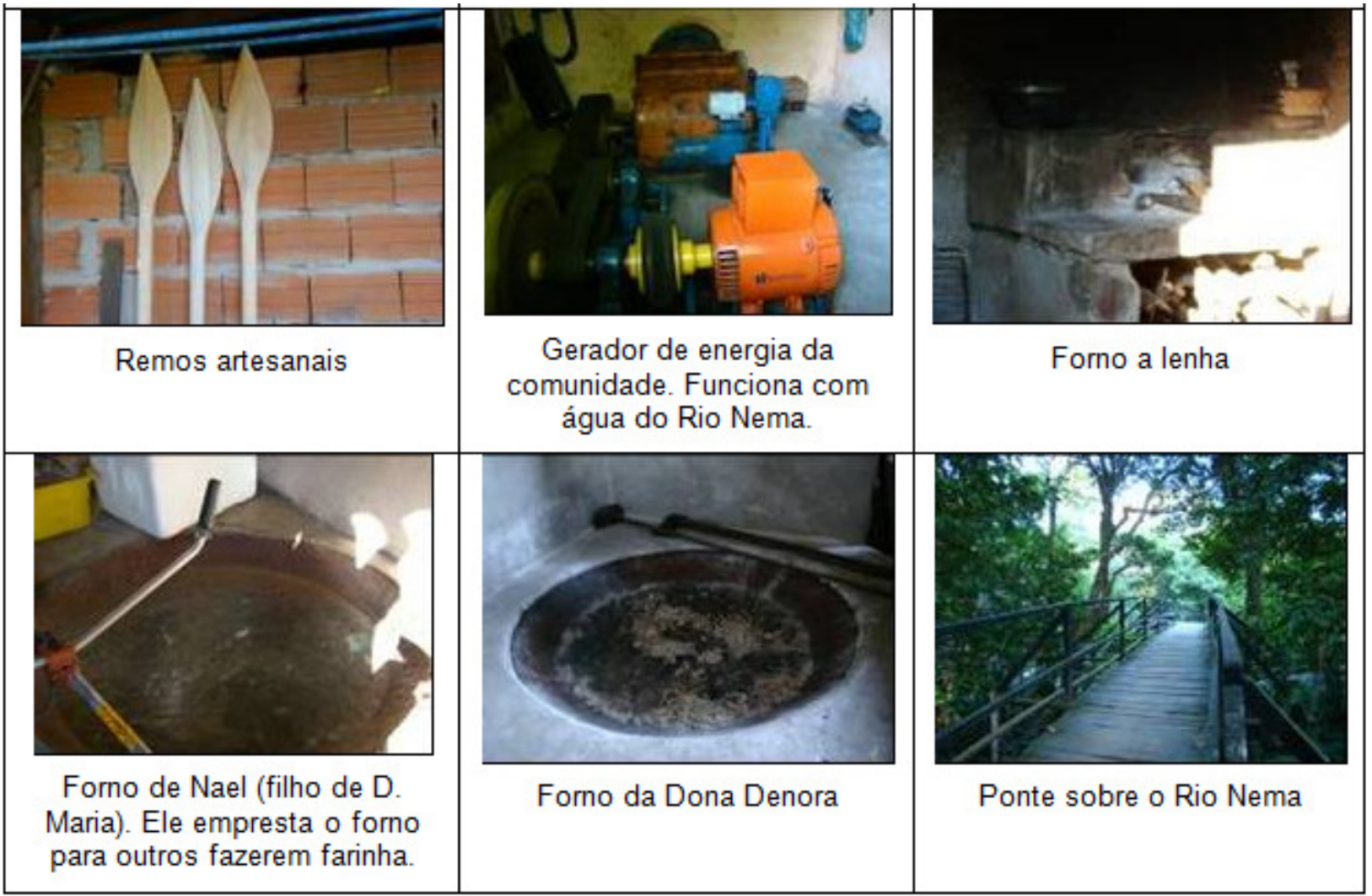

Foram discutidas as seguintes características de um bom condutor: ser atencioso e firme, comunicativo e objetivo, alegre e controlado, ter simpatia sempre, iniciativa, disciplina, boa saúde e resistência, criatividade, etc. E a seguinte postura profissional: Um bom condutor deve ter pontualidade, higiene pessoal, sorriso; ser o último a se servir durante as refeições depois de verificar que seus clientes estão bem servidos; ter uma boa apresentação pessoal, etc.
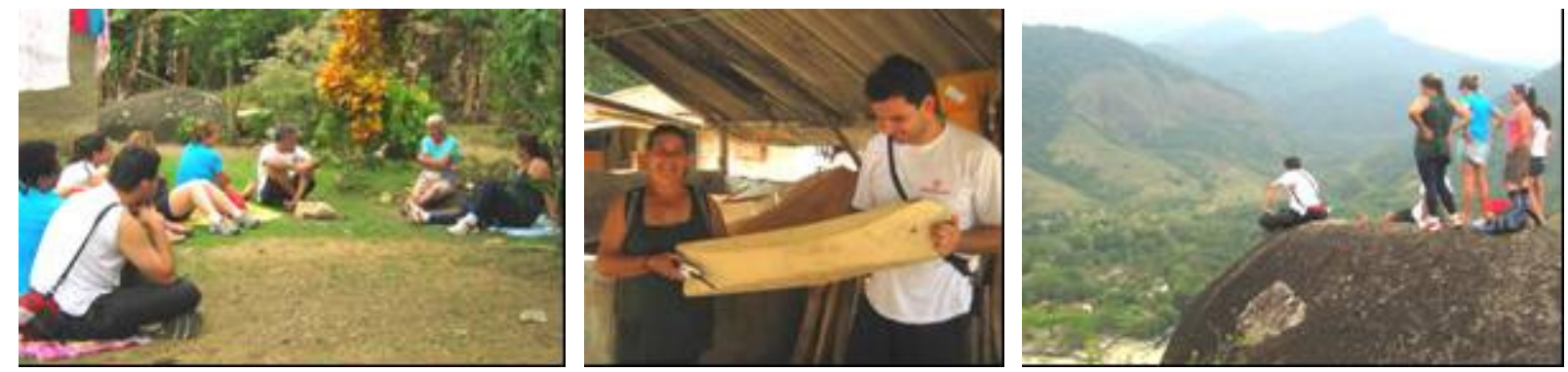

Figura 4: roteiro de turismo comunitário

Figure 4: community tourism tour "Bonete tradição caiçara". 
Projeto de turismo de base comunitária: comunidade tradicional do Bonete, llhabela (SP)

Após a consideração desses pontos, foi lido pelo grupo algumas recomendações básicas para o grupo que está sendo conduzido em Áreas naturais e em seguida foram discutidos os aspectos básicos de uma explanação durante a visita, em diferentes ambientes/situações, por exemplo, Unidade de Conservação.

\section{Conclusões e recomendações}

A realização das Oficinas de Planejamento Participativo de Turismo Comunitário, foi muito importante para uma visão mais ampla do turismo no Bonete. A presença dos participantes mostrou o comprometimento de membros da comunidade realmente interessados em fazer a diferença contribuindo para o desenvolvimento de um turismo responsável, que favoreça a comunidade através da geração de renda, conservação ambiental e fortalecimento comunitário e da cultura e das boas tradições, ao mesmo tempo. Foi identificada a autêntica vocação do local para a realização do Turismo de Base Comunitária, para o qual, o planejamento participativo é essencial.

Através das oficinas de "construção de conceitos" pôde-se perceber o grande valor de uma comunidade, onde há uma responsabilidade coletiva para tornar a vida melhor, pois as pessoas têm objetivos comuns. Percebeu-se também que, através da tradição, os moradores do Bonete guardam uma cultura viva, rara, de um modo de vida simples, por exemplo: pessoas que fazem suas roças, fabricam farinha de mandioca, canoas e pescam artesanalmente. O Turismo de Base Comunitária deve contribuir para o desenvolvimento socioeconômico do destino e manutenção de seu modo de vida tradicional.

Ao identificar os componentes da oferta turística (recursos, atrativos, equipamentos e serviços), os atores do turismo podem planejar melhor o que cada um pode fazer e, como a comunidade, como um todo, pode se beneficiar do turismo. Foi visto que estão todos interligados na cadeia de turismo, e que parcerias são fundamentais para uma melhoria da prestação de serviços, sem perder a autenticidade da comunidade.

Os valores da comunidade devem ser considerados acima de tudo. O desenvolvimento do turismo poderá ajudar a fortalecê-los, mas nunca impactá-los negativamente. Portanto, é necessário pensar nos impactos do turismo a longo prazo.

Sobre a elaboração de produtos turísticos de turismo de base comunitária, espera-se que o exercício tenha contribuído como ferramenta para transformar os muitos recursos do Bonete em atrativos, sempre seguindo um padrão de ótima qualidade e melhoria contínua dos serviços.

Por estar localizada no entorno de uma Unidade de Conservação (UC) - o Parque Estadual de Ilhabela - a proposta do projeto Turismo de Base Comunitária, segue os princípios para a visitação em UC, apontados nas Diretrizes para Visitação em Unidades de Conservação.

Além disso, o projeto de Turismo de Base Comunitária, através das oficinas 
realizadas, buscou fortalecer a comunidade, emponderando-a através do planejamento da atividade de turismo comunitário e sua gestão, tendo como norte as Diretrizes para a Participação das Comunidades Locais e Populações Tradicionais na Gestão da Visitação em Unidades de Conservação, ao mesmo tempo, em que recomenda e incentiva os Gestores do Parque Estadual de Ilhabela, que as implementem em todas as comunidades tradicionais de Ilhabela, incluindo o Bonete.

É importante notar que este trabalho representa apenas um passo na longa caminhada para o desenvolvimento do turismo esperado. Mas ela não é solitária. Estamos todos juntos nesta trilha preparando um novo caminho para um turismo mais justo e responsável para as nossas e as futuras gerações. E aí? O que estas mãos vão fazer?!

\section{Agradecimentos}

Agradecemos aos moradores da Comunidade Tradicional do Bonete, ao Instituto Costa Brasilis, em especial à Professora Márcia Regina Denadai, ao Centro Experimental em Desenvolvimento Sustentável (CEDS-LN) e à Câmara Técnica de Comunidades Tradicionais do Parque Estadual de Ilhabela.

\section{Referências bibliográficas}

BALANZÁ, I.M.; NADAL, M.C. Marketing e comercialização de produtos turísticos. São Paulo: Pioneira Thomson Learning, 2003.

BARTHOLO, R.; SANSOLO, D.G.; BURSZTYN, I. (orgs). Turismo de Base Comunitária - diversidade de olhares e experiências brasileiras. Letra e Imagem. 2009.

BORGES, M.M. In: MITRAUD, S. (org). Manual de Ecoturismo de Base Comunitária: ferramentas para um planejamento responsável. Publicação do Programa de Turismo e Meio Ambiente do WWF-Brasil. Brasília: WWF Brasil, 2003.

JÁNER, A.; MOURÃO, R. In: MITRAUD, S. (org). Manual de Ecoturismo de Base Comunitária: ferramentas para um planejamento responsável. Publicação do Programa de Turismo e Meio Ambiente do WWF-Brasil. Brasília: WWF Brasil, 2003.

MINISTÉRIO DO MEIO AMBIENTE. Manual Indígena de Ecoturismo - Brasília, 1997. 56p. (Grupo Técnico de Coordenação de Ecoturismo para a Amazônia Legal Execução: Instituto EcoBrasil Ecoturismo - Turismo Sustentável)

ORTIZ MONTEIRO, P.D.E.B.S.C. A participação e a percepção da comunidade local para o planejamento do ecoturismo no parque estadual da serra do mar Núcleo Picinguaba, bairro do Cambury, Ubatuba-SP. 2005. 275 f. Tese (Doutorado em Ciências Ambientais) - UNITAU - Universidade de Taubaté. Taubaté.

ORTIZ, R. Mundialização e cultura. São Paulo: Brasiliense, 2006.

Página 1068 Revista Brasileira de Ecoturismo, São Paulo, v.6, n.5, nov 20I3-jan 20I4, pp.1052-1069. 
ROTEIRO TURÍSTICO DO MEXILHÃO. Disponível em: http:// mexilhao.incubadora.fapesp.br/portal/sobre-o-projeto/quickdoc.2008-1031.1943520322/. Acesso em: 19 jan. 2010.

SALVATI, S.S. O WWF Brasil e o Turismo Responsável. Manual de Ecoturismo de Base Comunitária: ferramentas para um planejamento responsável. Publicação do Programa de Turismo e Meio Ambiente do WWF-Brasil. Brasília: WWF Brasil, 2003.

SENAR (Serviço Nacional de Aprendizagem Rural). Disponível em: http:// www.faespsenar.com.br/senar/progr/turural/turismo.htm. acesso em: 19 jan. 2010.

UNIVERSIDADE SÃO JUDAS TADEU. São Judas e o Projeto Quilombo: uma parceria cultural e social. Disponível em: http://www.usit.br/proex/inclusao social.php. Acesso em: 10 nov. 2009.

Mariane Carla Checon Salvador: Maitaca Ecoturismo, Caraguatatuba, SP, Brasil. Email:mari_checon@hotmail.com

Roberta Pedroso: ETEC São Sebastião, São Sebastião, SP, Brasil. Email: robsturismo@hotmail.com

Fátima Bezerra Bastos: MORPHO - Turismo de Experiência, São Paulo, SP, Brasil. Email: fatimabbastos@gmail.com

Data de submissão: 26 de junho de 2012

Data de recebimento de correções: 17 de setembro de 2013

Data do aceite: 04 de novembro de 2013

Avaliado anonimamente 